\title{
Article
}

\section{Attitudes toward intimate partner "honor"-based violence in India, Iran, Malaysia and Pakistan}

Lowe, Michelle, Khan, Roxanne, Thanzami, Vanlal, Barzy, Mahsa and Karmaliani, Rozina

Available at http://clok.uclan.ac.uk/21656/

Lowe, Michelle, Khan, Roxanne ORCID: 0000-0002-3485-2450, Thanzami, Vanlal, Barzy, Mahsa and Karmaliani, Rozina (2018) Attitudes toward intimate partner "honor"-based violence in India, Iran, Malaysia and Pakistan. Journal of Aggression, Conflict and Peace Research, 10 (4). pp. 283-292. ISSN 17596599

It is advisable to refer to the publisher's version if you intend to cite from the work. http://dx.doi.org/10.1108/JACPR-09-2017-0324

For more information about UCLan's research in this area go to http://www.uclan.ac.uk/researchgroups/ and search for <name of research Group>.

For information about Research generally at UCLan please go to http://www.uclan.ac.uk/research/

All outputs in CLoK are protected by Intellectual Property Rights law, including Copyright law. Copyright, IPR and Moral Rights for the works on this site are retained by the individual authors and/or other copyright owners. Terms and conditions for use of this material are defined in the policies page.

\section{CLoK}

Central Lancashire online Knowledge www.clok.uclan.ac.uk

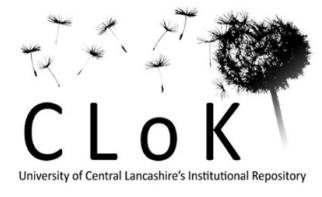




\section{Attitudes towards Intimate Partner 'Honor' Based Violence in India, Iran, Malaysia and Pakistan}

\begin{tabular}{|r|l|}
\hline Journal: & Journal of Aggression, Conflict and Peace Research \\
\hline Manuscript ID & JACPR-09-2017-0324.R1 \\
\hline Manuscript Type: & Empirical Paper \\
\hline Keywords: & $\begin{array}{l}\text { 'Honor'-based violence, intimate partner violence, perceptions, cultural } \\
\text { factors, Collectivist cultures, Attitudes }\end{array}$ \\
\hline \multicolumn{2}{|l}{} \\
\hline
\end{tabular}

SCHOLARONE ${ }^{m}$

Manuscripts 


\section{Purpose}

Although intimate partner violence (IPV) and 'honor'-based violence (HBV) are major concerns throughout the world, little research has investigated the acceptance of these forms of abuse outside of the West. This study therefore responds to this gap in the literature by exploring attitudes towards HBV in a fictional depiction of IPV across four Asian samples: India, Iran, Malaysia and Pakistan.

\section{Design/methodology/approach}

Participants $(\mathrm{n}=579)$ read a hypothetical scenario in which a husband, despite his own marital infidelity, verbally abuses and physically assaults his wife after discovering that she has been unfaithful. Participants then completed a questionnaire that assessed perceptions of damage to the husband's honor, approval of intimate partner HBV against the wife, and perceptions of both the victim-wife and the perpetrator-husband.

\section{Findings}

Findings revealed that more males than females, across all four nations, were endorsing of honor-adhering attitudes in response to the perceived threat to the husband's reputation resulting from the wife's infidelity. Additionally, of the four samples, Pakistani participants were the most approving and Malaysians least endorsing of honor-adhering attitudes.

\section{Originality/value}

Results are discussed in relation to studies of honor-adherence in Asian populations. This study provides an original glimpse into the perceptions of intimate partner HBV in these not-often sampled nationalities.

\section{Keywords}

'Honor'-based violence, intimate partner violence, perceptions, cultural factors 


\section{Attitudes towards intimate partner 'honor' based violence in India, Iran, Malaysia and Pakistan}

Intimate partner violence (IPV) is a major concern for health, criminal justice, and economies worldwide (Dietrich \& Schuett, 2013). Global prevalence is high, with cultural factors influencing both the rates of IPV and attitudes towards the acceptability of using this form of violence (Madhani et al., 2017. For example, evidence suggests that IPV disproportionately affects women from honor cultures in parts of Asia (Mayeda \& Vijaykumar, 2016). For instance, data from over 69,000 Indian women who completed the 2005-2006 National Family Health Survey indicated that in the 12 months prior to the study, 31 percent had been victims of physical abuse and 8 percent of sexual abuse at home (Kimuna, Djamba, Ciciyrkaite, \& Cherukuri, 2012). In a study of 400 Iranian women, a notable proportion reported that they had experienced psychological/verbal (58\%), physical (29\%), and sexual abuse (10\%) (Sheikhbardsiri, Raeisi, \& Khademipour, 2017). More specifically, the most recent Human Rights Commission of Pakistan (HRCP) annual report (2015) cites that in the last three years alone, around 2,300 women have been victims of 'honor' killing. Other sources indicate that on average there are more than 10,000 'honor' killings per year in just this one nation alone (Kirti, Kumar, \& Yadav, 2011). It is estimated that Pakistan has the highest global rate of 'honor' killing (HRCP, 2015).

Cultures of honor place a high premium on a family's respectable social image (Brown, Osterman, \& Barnes, 2009). A core expectation in honor cultures, which are collectivist and patriarchal in structure, is that females and males adhere to strict gender roles (Galanti, 2003; Rivera et al., 2008). This social expectation dictates that females demonstrate their worth by exhibiting loyalty, humility, unconditional compliance, and submissiveness to their male relatives (Cohen \& Nisbett, 1994; Rodriguez Mosquera, Manstead, \& Fischer, 2002; Vandello, 2016). Males, on the other hand, acquire honor if they act tough and, if deemed necessary, use aggressive force to protect or restore their own, and by association, their family's honorable reputation (Vandello, 2016).

The collectivist cultural system promotes an ideology in which both the community and family apply pressure on married couples to ensure that wives submit to their husband's authority, stand behind his decisions, tolerate his actions, and remain faithful (Galanti, 2003; 
Moreno, 2007; Vandello \& Cohen, 2003). In this way, the social hierarchy of honor cultures result in male dominance over female counterparts (Torres, Solberg, \& Carlstrom, 2002), and socially legitimizes the use of 'honor'-based violence (HBV) as a means of restoring moral order (Vandello, 2016). Violation of the feminine honor code (e.g., sexual immodesty or having an extra-marital affair) in particular, can threaten a husband's (and his family's) reputation and this type of situation results in high rates of HBV (Ahrens, Rios-Mandel, Isas, \& Lopez, 2010). The demands of meeting this cultural expectation are such that both female and male family members may encourage one another to use aggressive means to uphold or protect the social perception of their family's good standing (Cohen \& Nisbett, 1994). This view is supported by a review of the attitudinal literature in which it was found that while females from collectivist honor cultures were less approving of HBV compared to their male counterparts, a notable proportion endorsed the use of abuse, violence, and killing other females in the name of family 'honor' (Khan, 2018).

While adultery is discouraged in many cultures, it carries a particularly harsh stigma in honor cultures that promote collectivism over individualism (Vandello \& Cohen, 2003). It is thus not surprising then that HBV is widely reported across many collectivistic cultures, for example, in the Mediterranean, North America, and Latin America (Dietrich \& Schuett, 2013; Vandello \& Cohen, 2003), as well as in Turkey (Doğan, 2014; Sev'er, 2012), the Middle Eastern and South Asian nations (Eisner \& Ghuneim, 2013; Nasrullah, Haqqi, \& Cummings, 2009).

Despite this, surprisingly few studies have examined attitudes towards HBV against intimate partners. Cultural factors are shown to determine whether victims perceive family violence to be abusive or not (Lira, Koss, \& Russo, 1999) as well as the likelihood of victims seeking help (Vandello, Cohen, Grandon, \& Franiuk, 2009). In studies with Latino populations, for example, those who adhered to honor-based cultural traditions were more accepting of violence against intimate partners than IPV that was unrelated to defending honor (Dietrich \& Schuett, 2013; Vandello et al., 2009). Additionally, Latino participants viewed IPV perpetrators more favorably when the violence was due to a threat of dishonoring a husband's or family's reputation, and they rated a wife more positively when she stayed with her violent husband than when she left the family home (Vandello et al., 2009). In short, attitudinal research highlights the importance of a husband's reputation when honor-adherent participants make judgements about victims and perpetrators in IPV situations, in line with the beliefs within those cultures. 
Similar to honor-adherent Latino samples (Vandello et al., 2009), the handful of studies conducted in Asian nations indicate that victims' perceptions of IPV are likely to be unconducive to help-seeking. For example, a study of pregnant Pakistani women found that while 47 percent perceived physical abuse to be a form of IPV, only 8 percent and 0.4 percent considered verbal and sexual abuse, respectively, to be violent (Madhani et al., 2017). Indeed, no women in Madhani et al's study sought professional help after being abused by their husband. This anomaly is perhaps better understood when viewed in context of social norms in Pakistan, which dictate that a husband controls his wife's sexuality, and she should be sexually available for him, readily and exclusively. Studies show that there is a powerful cultural norm in Pakistan, by which it is socially acceptable for a husband to maintain that his wife deserves 'sarzanish' (in Urdu, a stern warning or symbolic humiliation) if she refuses sex or is unfaithful (Fikree, Razzak, \& Durocher, 2005). Similar to the Western term 'cuckold', husbands in Pakistan who fail to chastise their wives for sexual immodesty are often regarded as an object of derision and are labeled as 'run mureed' (a wife's subservient).

This study is the first multi-nation investigation to explore attitudes towards a husband's use of HBV against his wife, across four Asian nations, namely India, Iran, Malaysia and Pakistan. Research conducted in these specific nations are a valuable addition to the limited but growing research conducted in comparable Middle Eastern, North African, South Asian and Turkish populations (see Khan, 2018). To obtain a degree of consistency across such diverse populations, a sample of university students from each nation was recruited for this study. The use of student participants also aligns with a majority of the extant HBV attitudinal research, thereby increasing the reliability of any comparisons made. This study explored the extent to which a husband's honor was perceived to be damaged by his wife's infidelity, and the acceptance of him using HBV against her when he found out. The following four attitudinal views were investigated: (1) perceived damage to a husband's honor, (2) approval of HBV in response to a wife's adultery, (3) perceptions of the victim-wife and (4) perpetrator-husband. In collectivist honor cultures, female adultery can be damaging to a husband's (and thereby, the family and community's) reputation (Vandello, 2016). Therefore, it is expected that there will be gender differences in perceptions of the husband's honor being damaged, approval of HBV against the wife, as well as perceptions of both the wife and the husband, with males being more endorsing of honor values than females. No previous studies have investigated attitudes towards 
HBV in these specific Asian nations. As these nations are collectivist-orientated honor cultures, it was expected that participants from all four countries would endorse acceptance of HBV to some extent, although based on previous research, it was predicted that attitudes would be particularly honor-endorsing in Pakistan compared with those of the other three nations.

\section{Method}

Design

The study employed a 4 (country of residence) x 2 (gender) between subjects design. Country of residence comprised participants from India, Iran, Malaysia, and Pakistan. Four dependent variables comprised items that measured participant's perceptions of damage to the husband's honor, their approval of his use of HBV against his wife, and perceptions pertaining to the characterological likeability of both the victim-wife and perpetrator-husband.

\section{Participants}

Data was collected from 579 (289 male; 290 female) participants of Asian ethnic origin across four countries of residence: India $(\mathrm{N}=141)$, Iran $(\mathrm{N}=124)$, Malaysia $(\mathrm{N}=164)$ and Pakistan $(\mathrm{N}=150)$. The Indian data was collected from two universities in Aizawl, the state capital of Mizoram, which is situated in the north-eastern region of India. Iranian data were collected from a university in the capital city, Tehran. The Malaysian data was collected from a university in the suburbs of Kuala Lumpu, and Pakistani data from Karachi, the capital of the Pakistani province of Sindh. Age ranged from 17-50 years $(M=23.45 ; S D=4.74)$. In total, 480 participants ascribed to a religious denomination, with $207(36 \%)^{1}$ reporting they were Muslim, 179 (31\%) Christian, $61(11 \%)$ Buddhist and 33 (6\%) Hindu. The majority of participants had been educated past 16 years, with 277 (48\%) having university-level education, 272 (47\%) further (post-16) education, and the remainder having been educated up to school-level (up to 16 years). The majority of participants were either single $(60 \%)$ or dating $(23 \%)$, with the remainder being married $(12 \%)$ separated, cohabiting or widowed (all $<1 \%)$.

\section{Materials}

\footnotetext{
${ }^{1}$ All percentages are rounded up.
} 
Based on measures used in a study to explore perceptions of damage to honor in Latino populations (see Dietrich \& Schuett, 2013), a questionnaire booklet was designed for the purpose of this study. Written instructions asked participants to provide demographic details including gender, age, and ethnic origin. Participants were then asked to read a hypothetical scenario before answering a set of questions used to measure their attitudes towards the intimate partner HBV depicted in that text. The scenario text was as follows:

Asfia/Kimi/Maryam ${ }^{2}$ and Pasha/Zuala/Ali have been having an affair for 6 months; they work together as teachers at a local college. Asfia/Kimi/Maryam's husband, Rizwa/Tluanga/Riza, had no idea of her infidelity although he himself was having an extramarital affair. He only became suspicious when he saw them holding hands in a photo taken at a college social event. When Asfia/Kimi/Maryam came home from work that night, Rizwa/Tluanga/Riza called her 'a whore', punched her to the ground and kicked her. He threatened that unless she ended her affair with Pasha/Zuala/Ali, he would kill her.

Participants were asked to answer four questions that examined perceptions of damage the husband's reputation, approval of his use of HBV against his wife, and views of both these protagonists respectively. Each response was rated along a 7-point Likert scale ranging from $1=$ strongly disagree to $7=$ strongly agree. The wording of each of the four dependent variables was as follows:

a. Damage to the husband's honor - Asfia/Kimi/Maryam has damaged her husband's honor by openly having an affair with Pasha/Zuala/Ali.

b. Approval of intimate partner HBV - It is reasonable to use violence in this circumstance.

c. Perceptions of the victim-wife - Asfia/Kimi/Maryam is a caring person.

d. Perceptions of the perpetrator-husband - Rizwa/Tluanga/Riza is reliable.

Procedure

A similar procedure was used across all samples for consistency across populations. In each country, a research team collected data from students at a number of colleges and universities campuses, using opportunity sampling. Adverts were placed around campuses with a

\footnotetext{
${ }^{2}$ The protagonists' names in the scenario were changed to reflect the country in which the questionnaires were distributed.
} 
website address so participants could complete the questionnaire online. Students, when approached on campus with paper copies, were verbally briefed about the study, and asked if they wished to participate. Those who agreed were provided with the questionnaire booklet to complete in their own time, and to return to a secure drop-in box. A detailed briefing and debriefing sheet, attached to the questionnaire, detailed the full research aims and informed them that participation was voluntary, confidential, responses were anonymous and that any information provided would be used for research purposes only. The project was fully approved by each participating institution's ethics committee guidelines.

\section{Results}

\section{Multivariate Effects}

Multivariate Analysis of Variance (MANOVA) was conducted to examine the influence that country of residence and gender had on perceptions of the perpetrator-husband's use of HBV across the four dependent variables. Significant multivariate effects were revealed for country of residence, Pillai's $=.52, F(12,1698)=29.76, p<.001$ and gender, Pillai's $=.04, F(4,564)=5.84$, $p<.001$. The interaction between country of residence and gender was non-significant, Pillai's $=0.20, F(12,1698)=.74, p=.72$. Subsequent univariate analyses on the significant main effects are detailed below.

\section{Gender}

Significant univariate main effects were revealed for two of the four dependent variables, namely: approval of intimate partner $\operatorname{HBV}, F(1,567)=13.01, \mathrm{p}<.001$; and perceptions of the victim-wife, $F(1,565)=6.40, p=.01$. Males were more approving of intimate partner HBV and considered the victim less likable than did females. Damage to the perpetrator-husband's honor, $F(1,567)=.62, p=.43$, and perceptions of the perpetrator-husband $\mathrm{F}(1,567)=3.59, p=.06$ were not significant, although perceptions of the perpetrator were marginal. See Table 1 for means and standard deviations.

\section{TABLE 1 ABOUT HERE}

\section{Country of Residence}


Significant univariate main effects were revealed for all four dependent variables across country of residence; namely, damage to the perpetrator-husband's honor, $F(3,567)=31.41$, $p<.001$, approval of intimate partner $\operatorname{HBV}, F(3,567)=122.26, p<.001$, perceptions of the victimwife, $F(3,567)=14.64, p<.001$ and perceptions of the perpetrator-husband, $F(3,567)=55.08$, $p<.001$.

Post hoc Tukey tests revealed that Pakistani participants were more strongly believing that the wife had caused damage to her husband's honor than were Indian, Iranian or Malaysian participants. Pakistani participants were more approving of the intimate partner HBV committed against the victim-wife than were Indian, Iranian or Malaysians. In a stepped effect, Indians were more approving of violence than Iranians or Malaysians. In turn, Malaysian participants were more highly disapproving of intimate partner HBV than participants from any of the other nations. In a similar stepped fashion, Pakistani participants had more positive views regarding the likeability of the perpetrator than participants from the other three nations. In turn, Iranians and Indians were more positive than Malaysians, who were more disapproving of the perpetrator-husband than participants from India, Iran and Pakistan were. Interestingly however, Pakistani, along with Iranian participants had more favorable perceptions of the victim-wife than did Indian or Malaysians. Table 2 displays the means and standard deviations.

\section{TABLE 2 ABOUT HERE}

\section{Discussion}

The gender differences revealed a partial confirmation of predictions. Specifically, although mean differences were small, males were significantly more approving of the perpetrator-husband's HBV towards his victim-wife and they regarded her less positively than did female participants. These findings align with research in honor-cultures that highlight the promotion of masculine dominance over female kin and expectations of a wife's loyalty, submissiveness and sexual faithfulness towards her husband (e.g., Torres et al., 2002; Vandello \& Cohen, 2003).

In evaluating this study's findings, it is important to remember that in Asian collectivist cultures, as those sampled for the present study, there is a social expectation for a husband to chastise his wife if she is perceived to violate the rigid gendered-honor code; if he does not, he 
himself brings shame upon both himself and his family (Zakar et al., 2013). It is perhaps unsurprising then that when compared to females, males were more approving of intimate partner HBV and more negative towards the victim-wife as the onus is very much upon males within honor-cultures to respond publically with aggressive machoism to uphold his and his family's honor (Cohen \& Nisbett, 1994; Khan, 2018), should a wife breach her gender role expectations.

Contrary to predictions, no gender differences were found for perceptions of damage to the husband's honor or how he was perceived. Interestingly, both males and females responded that the husband's honor had been damaged by the wife's infidelity. This implies that within honor-cultures, males and females endorse honor-based beliefs in similar measure, and both believe that female infidelity to be damaging to a husband's reputation.

More broadly, these findings may seem paradoxical in light of a large volume of research that has found that typically, females in contrast to males, are more likely to blame men who perpetrate intimate partner violence against women (see Eigenberg \& Policastro, 2016; Flood \& Pease, 2009). Yet a different pattern is beginning to emerge in piecing together findings from the growing research conducted in Asian collectivist honor cultures in relation to HBV (see Khan, 2018). For example, in a study of 601 members of the public in Pakistan, upon reading a hypothetical scenario, over half the females (53\%) interviewed approved of a husband killing his wife in the name of so called 'honor', after witnessing her in an extramarital relationship with a stranger (Shaikh, Shaikh, Kamal, \& Mashood, 2010). It was also notable just under threequarters of these females (71\%) thought that the husband should not forgive his wife, and over a half (57\%) thought the husband should divorce her, and ask her to leave his house straight away. A study of British South Asians (a majority of Indian and Pakistani origin), found that while a comparably small percentage supported using HBV against a female, if she had dishonored her family, about one-fifth (18\%) of both males and females agreed that HBV was justifiable for disobeying her father $(8 \%)$, marrying someone unacceptable $(7 \%)$ or wanting to end her marriage (7\%) (ComRes, 2012). While significant gender differences were not reported in this and other studies with comparable diasporic British Asians populations (e.g., Khan, Saleem, \& Lowe, 2017), they do indicate that in collectivist communities that have migrated from Asia, there is a degree of acceptance for using HBV against females who break honor-codes (Brandon 
\& Hafez, 2010). This has wide-reaching implications for the perpetuation of intimate partner HBV globally (Hayes, Freilich, \& Chermak, 2016).

It was predicted that all four nations would express honor-endorsing attitudes to some extent, although Pakistani participants were expected to have more negative honor-endorsement than Indians, Iranians and Malaysians. As predicted, findings confirmed that participants across all four nations (as collectivist-patriarchal cultures) endorsed intimate partner HBV to some extent. Results across the four measures were consistent in showing that Malaysians were the least honor-endorsing, least condoning of intimate partner HBV, and less positive towards the perpetrator-husband than the other nations, while as expected, Pakistani participants were the most honor-endorsing, most approving of intimate partner HBV, and had the highest positive perception of the perpetrator-husband. Perhaps this finding is not altogether surprising given that Pakistan is estimated to have the highest worldwide rate of 'honor' killing (HRCP, 2015).

The present study is not without limitation. Although the participant age-range was wide, the mean age revealed that a majority of the participants were young adults with relatively high educational achievements, recruited from university settings. As such, their opinions may not be representative of their older or less-educated counterparts (Lown \& Vega, 2001). Additionally, although some demographic data was collected, research suggests that factors such as socioeconomic status (West, Kaufman Kantor, \& Jasinski, 1998), and coming from an urban versus rural background (Moracco, Hilton, Hodges, \& Frasier, 2005) may be associated with attitudes toward IPV and HBV (Brandon \& Hafez, 2010; Eisner \& Ghuneim, 2013; Shaikh, Kamal, \& Naqvi, 2015) therefore should be accounted for in future studies.

A number of factors restricted the generalizability of the current findings, including the use of just one hypothetical scenario upon which to test the attitudinal measures. Although hypothetical scenario studies lack ecological validity relevant to real cases, they are frequently utilized in attitudinal research, and provide an ethical means by which to test sensitive topics in a way not possible if depictions of real cases were used (see e.g., Schoenberg \& Ravdal, 2000; Sleed, Durrheim, Kriel, Solomon, \& Baxter, 2002 for further discussion). Previous studies have also used this method to collect data on participants' perceptions of HBV in Asia, including Pakistan (e.g., Shaikh et al., 2010; Shaikh et al., 2015). Additionally, hypothetical scenarios provide a scientific way to test specific variables while not confounding results by including extraneous factors that may be apparent in real and uncontrolled cases. Still, it is recognized that 
this study used only one vignette to depict a husbands' use of intimate partner HBV against his wife, in response to her infidelity, where the perceived damage to honor was public. Participants may have responded differently to a situation that depicted a perceived affront to honor that was not public (Dietrich \& Schuett, 2013), did not depict marital infidelity, or one in which the victim was male and the perpetrator was female. Therefore, it would be advantageous for future studies to test judgements towards HBV that involve other violent situations that arise through means other than infidelity, involving protagonists in relationships other than that of marital partners.

This study is the first multi-nation investigation in Asia that explores attitudes towards intimate partner HBV. To see if the current findings can be replicated, future research could recruit to compare the attitudes of multiple-samples of participants from a number of collectivist cultures, including those from the Middle East and South Asia (Eisner \& Ghuneim, 2013; Vandello, 2016). There is also scope for cross-cultural studies to compare attitudes towards intimate partner HBV in collectivist cultures (with both native and diasporic populations) with individualist cultures where HBV has been reported in Europe, such as Germany (Grzyb, 2016), Finland (Keskinen, 2009), Sweden (Wikan, 2008), and across North America (Chelser, 2009; Hayes et al., 2016). The current findings permit a more nuanced understanding of the role of culture in the acceptance of intimate partner HBV. This will aid the development of more effective education, intervention, and prevention programs that increase awareness and support options with these difficult to identify and reach populations.

Yet, it is important to acknowledge then that individuals' adherence to collectivist honor principles may act as an obstacle to victim help-seeking (Khan, 2007). It is also important not to overlook the attitudes of professionals who are likely to have direct contact with HBV victims in practice settings. For example, although health and emergency services workers are in place to provide support for those vulnerable to this form of abuse, studies have found that nursing staff, in-training to work within healthcare services in collectivist cultures, would condone the use of violence (even murder) if committed to protect 'honor' (Can \& Edirne, 2010). Clearly, there is a pressing need for attitudinal change programs in collectivist honor cultures, to train professionals in the safeguarding arena, including police, social welfare, health, education services. (e.g., Meyeda \& Vijaykumar, 2016; Sedem-Wreder, 2015). An innovative attitude change program in 
Sweden called "Sharaf Heroes" is a laudable exemplar of how interventions might be designed to engage young male populations to address attitudes that condone the use of HBV (Rexvid \& Schlytter, 2012). This long-term program offers educational workshops and courses where men from different cultural and religious backgrounds attend courses about human rights and equality, where they are encouraged to discuss the patriarchal origins and detrimental consequences of HBV. Once they complete a course, a 'qualified' Hero can then themselves deliver a workshop in schools, organisations, and authorities. This program has been rolled out to a number of Swedish cities, and across other countries, such as France, Holland, Norway and Germany (Rexvid \& Schlytter, 2012). Practical developments, such as these, may prove to be influential in changing attitudes towards $\mathrm{HBV}$, as they implicitly require participation and engagement from males raised in patriarchal, collectivist cultures, who are most 'at risk' of perpetuating HBV beliefs, and so their insight could play a part in a program's success.

In conclusion, this multi-nation attitudinal study provides a novel overview of how individuals from Asian collectivist cultures differ in their perceptions of intimate partner HBV. Due to the populations sampled, and for the specific focus on intimate partner HBV, this study's findings add to the growing research in this previously overlooked area. The current findings also have applied value and could guide practice efforts in combating perpetrators' HBVsupportive attitudes that endorse the use of violence as a means of maintaining family honor. There is also scope for exploring factors other than that of culture, including psychosocial risk and protective factors already established in the aggression literature, which may influence the development of prosocial attitudes that discourage the use of violence against intimate partners in the name of so called 'honor'.

\section{References}

Ahrens, C.E., Rios-Mandel, L. Isas, L. \& Lopez, M. (2010). Talking about interpersonal violence: Cultural influences on Latina' identification and disclosure of sexual assault and intimate partner violence. Psychological Trauma: Theory, Research, Practice and Policy, 2, 284-295. doi: 10.1037/a0018605 
Aplin, R. (2017). Exploring the role of mothers in 'honor' based abuse perpetration and the impact on the policing response. Women's Studies International Forum, 60, 1-10. doi.org/10.1016/j.wsif.2016.10.007

Brandon, J., \& Hafez, S. (2010). Crimes of the community: Honour-based violence in the UK. Centre for Social Cohesion. London.

Brown, R.P., Osterman, L.L., \& Barnes, C.D. (2009). School violence and culture of honor. Psychological Science, 20, 1400-1405. doi: 10.1111/j.14679280.2009.02456.x

Can, M. \& Edirne, T. (2011). Beliefs and attitudes of final-year nursing students on honor crimes: a cross-sectional study. Journal of Psychiatric and Mental Health Nursing, 18, 736-743.

Cohen, D. \& Nisbett, R.E. (1994). Field experiments examining the culture of honor: The role of institutions in perpetuating norms about violence. Personality and Social Psychology Bulletin, 20, 551-567. doi: 10.1177/0146167294205012

ComRes (2012). BBC Panorama Honor Crime Survey. A survey of young British Asians conducted on behalf of BBCPanorama. Retrieved from http://www.comresglobal.com/polls/bbc-panorama-honor-crime-survey/

Dietrich, D.M. \& Schuett, J.M. (2013). Culture of honor and attitudes toward intimate partner violence in Latinos. Sage Open, 3, 1-11. doi: 10.1177/2158244013489685

Doğan, R. (2014). The profiles of victims, perpetrators, and unfounded beliefs in honor killings in Turkey. Homicide Studies, 18(4), 389-416. doi. 10.1177/1088767914538637

Eigenberg, H., \& Policastro, C. (2016). Blaming Victims in Cases of Interpersonal Violence: Attitudes Associated With Assigning Blame to Female Victims. Women \& Criminal Justice, 26(1), 37-54. doi.org/10.1080/08974454.2014.997417

Eisner, M., \& Ghuneim, L. (2013). Honor killing attitudes amongst adolescents in Amman, Jordan. Aggressive Behavior, 39(5), 405-417. doi. 10.1002/ab.21485

Fikree, F.F., Razzak, J.A. \& Durocher, J. (2005). Attitudes of Pakistani men to domestic violence: A study from Karachi, Pakistan. Journal of Men's Health and Gender, 2, 49-58. 
Flood, M. \& Pease, B. (2009). Factors influencing attitudes to violence against women, Trauma, Violence, \& Abuse, 10, 125-142. doi. 10.1177/1524838009334131

Galanti, G. (2003). The Hispanic family and male-female relationships: An overview. Journal of Transcultural Nursing, 14, 180-185. doi: 10.1177/1043659603014003004

Grzyb, M. A. (2016). An explanation of honour-related killings of women in Europe through Bourdieu's concept of symbolic violence and masculine domination, Current Sociology, 64, 1036-1053.

Hayes, B. E., Freilich, J. D., \& Chermak, S. M. (2016). An exploratory study of honor crimes in the United States. Journal of Family Violence, 31(3), 303-314. doi.org/10.1007/s10896016-9801-7

Henry, P.J. (2009). Low-status compensation: A theory for understanding the role of status in cultures of honor. Journal of Personality and Social Psychology, 97, 451-466. doi: $10.1037 / \mathrm{a} 0015476$

Keskinen, S. (2009). 'Honour-related violence' and Nordic nation-building. In S. Keskinen, S. Tuori, S. Irni, \& D. Mulinari, (Eds). Complying with Colonialism. Gender, Race and Ethnicity in the Nordic Region. Farnham: Ashgate, pp. 257-272.

Khan, R. (2007). Honour-Related Violence (HRV) in Scotland: A cross-and multi-agency intervention involvement survey. Internet Journal of Criminology, 1-8.

Khan, R. (2018). Attitudes towards 'honor' violence and killings in collectivist cultures: Gender differences in Middle Eastern, North African, South Asian (MENASA) and Turkish populations. In J. L. Ireland, P, Birch, \& C. A. Ireland (Eds.), International Handbook in Aggression: Current Issues and Perspectives, Chapter 6, (pp. 216-226). London: Routledge.

Khan, R., Saleem, S. and Lowe, M. (2017). 'Honor'-based violence in a British South Asian community, Safer Communities. doi.10.1108/SC-02-2017-0007

Kimuna, S.R., Djamba, Y.K., Ciciyrkaite, G. \& Cherukuri, S. (2012). Domestic violence in India. Insights from the 2005-2006 National Family Health Survey, Journal of Interpersonal Violence, 28, 773-807. doi: 10.1177/0886260512455867 
Lira, L., Koss, M.P. \& Russo, N. (1999). Mexican American women's definitions of rape and sexual abuse. Hispanic Journal of Behavioral Sciences, 21, 236-265. doi:

\subsection{7/0739986399213004}

Lown, E. \& Vega, W.A. (2001). Prevalence and predictors of physical partner abuse among Mexican American women. American Journal of Public Health, 91, 441-445.

Madhani, F.I., Karmaliani, R., Patel, C., Bann, C.M., McClure, E.M., Pasha, O \& Goldenberg, R.L. (2017). Women's perceptions and experiences of domestic violence: An observational study from Hyderabad, Pakistan. Journal of Interpersonal Violence, 32, 76100. doi: $10.1177 / 0886260515585533$

Mayeda, D.T. \& Vijaykumar, R. (2016). A review of the literature on honor-based violence. Sociology Compass, 10, 353-363. doi: 10.1111/soc4.12367

Moracco, K., Hilton, A., Hodges, K. \& Frasier, P. (2005). Knowledge and attitudes towards intimate partner violence among immigrant Latinos in rural Carolina. Violence against Women, 11, 337-352. doi: 10.1177/1077801204273296

Moreno, C.L. (2007). The relationship between culture, gender, structural factors, abuse, trauma, and HIV/AIDS. Qualitative Health Research, 17, 340-352. doi: $10.1177 / 1049732306297387$

Nasrullah, M., Haqqi, S. and Cummings, K. J. (2009). 'The epidemiological patterns of honor killing of women in Pakistan', The European Journal of Public Health, 19: 193-197. doi.org/10.1093/eurpub/ckp021

Rexvid, D., \& Schlytter, A. (2012). Heroes, hymen and honour: A study of the character of attitude change among male youth with their roots in an honour-based context. Review of European Studies, 4(2), 22-32. doi.org/10.5539/res.v4n2p22

Rivera, F.I., Guarnaccia, P.J., Mulvaney-Day, N., Lin, J.Y., Torres, M. \& Alegria, M. (2008). Family cohesion and its relationship to psychological distress among Latino groups. Hispanic Journal of Behavioral Sciences, 30, 357-378. doi: 10.1177/0739986308318713 
Rodriguez Mosquera, P., Fischer, A.H., Manstead, A.R., \& Zaalberg, R. (2008). Attack, disapproval or withdrawal? The role of honour in anger and shame responses to being insulted. Cognition and Emotion, 22, 1471-1498. doi: 10.1080/02699930701822272

Rodriguez Mosquera, P., Manstead, A.R. \& Fischer, A.H. (2002). The role of honor concerns in emotional reactions to offences. Cognition and Emotion, 16, 143-163. doi: $10.1080 / 02699930143000167$

Schoenberg, N. E., \& Ravdal, H. (2000). Using vignettes in awareness and attitudinal research. International Journal of Social Research Methodology, 3(1), 63-74.

Sedem, M. \& Ferrer-Wreder, L. (2015). Fear of the loss of honor: implications of honor-based violence for the development of youth and their families. Child Youth Care Forum, 44(2), 225-237. doi.org/10.1007/s10566-014-9279-5

Sev'er, A. (2012). In the name of fathers: honor killings and some examples from South-Eastern Turkey, Atlantis: Critical Studies in Gender, Culture \& Social Justice, 30, 129-145.

Shaikh, M. A., Kamal, A. \& Naqvi, I. (2015). Opinions of university students on honor killings: Perspective from Islamabad and Rawalpindi. Journal of the Pakistan Medical Association, 65, 421-424.

Shaikh, M. A., Shaikh, I. A., Kamal, A. \& Masood, S. (2010). Attitudes about honor killing among men and women-perspective from Islamabad, J Ayub Med Coll Abbottabad, 22, 38-41.

Sheikhbardsiri, H., Raeisi, A. \& Khademipour, G. (2017). Domestic violence against women working at four educational hospitals in Iran. Journal of Interpersonal Violence. doi: $10.1177 / 0886260517719539$

Sleed, M., Durrheim, K., Kriel, A., Solomon, V., \& Baxter, V. (2002). The effectiveness of the vignette methodology: A comparison of written and video vignettes in eliciting responses about date rape. South African Journal of Psychology, 32(3), 21-28.

Torres, J.B., Solberg, V.H. \& Carlstrom, A.H. (2002). The myth of sameness among Latino men and their machismo. American Journal of Orthopsychiatry, 72, 163-181. doi: 10.10337/0002-9432.72.2.163 
Vandello, J. (2016). Do we need a psychology of women in the Islamic world? Sex Roles, 75, 623-629. doi: 10.1007/s1199-016-0691-1

Vandello, J.A., Cohen, D., Grandon, R. \& Franiuk, R. (2009). Stand by your man: Indirect prescriptions of honorable violence and feminine loyalty in Canada, Chile, and the United States. Journal of Cross Cultural Psychology, 40, 81-104. doi:

$10.1177 / 022022108326194$

Vandello, J.A. \& Cohen, D. (2003). Male honor and female fidelity: Implicit cultural scripts that perpetuate domestic violence. Journal of Personality and Social Psychology, 84, 9971010. doi: 10.1037/0022-3514.84.5.997

West, C.M., Kaufman Kantor, G. \& Jasinski, J.L. (1998). Sociodemographic predictors and cultural barriers to help-seeking behaviors in Latina and Anglo American women. Violence and Victims, 13, 361-375.

Wikan, U. (2008). In Honor of Fadime: Murder and Shame. University of Chicago Press. Zakar, R., Zakar, M.Z. \& Kraemer, A. (2013). Men's beliefs and attitudes toward intimate partner violence against women in Pakistan. Violence against Women, 19, 246-268. doi: $10.1177 / 107801213478028$ 
Table 1: Means and Standard Deviations across Participant Gender

\begin{tabular}{|c|c|c|c|}
\hline Dependent Variable & Gender & Mean & SD \\
\hline \multirow{2}{*}{$\begin{array}{l}\text { Damage to Perpetrator- } \\
\text { Husband's Honor }\end{array}$} & Male & 5.15 & 1.78 \\
\hline & Female & 5.05 & 1.91 \\
\hline \multirow{2}{*}{$\begin{array}{l}\text { Approval of Intimate } \\
\text { Partner HBV }\end{array}$} & Male & 3.34 & 1.84 \\
\hline & Female & 3.00 & 1.85 \\
\hline \multirow[t]{2}{*}{ Perceptions of Victim-Wife } & Male & 3.51 & 1.61 \\
\hline & Female & 3.83 & 1.51 \\
\hline Perceptions of Perpetrator- & Male & 3.35 & 1.78 \\
\hline Husband & Female & 3.14 & 1.65 \\
\hline
\end{tabular}


Table 2: Means and Standard Deviations across Country of Residence

\begin{tabular}{llll} 
Dependent Variable & Country & Mean & SD \\
\hline Damage to Perpetrator-Husband's & & & \\
Honor & India & 4.92 & 1.88 \\
& Iran & 4.44 & 1.91 \\
& Malaysia & 4.70 & 1.70 \\
& Pakistan & 6.24 & 1.35
\end{tabular}

Approval of Intimate Partner HBV

$\begin{array}{lll}\text { India } & 3.12 & 1.67 \\ \text { Iran } & 2.97 & 1.38 \\ \text { Malaysia } & 1.75 & 1.26 \\ \text { Pakistan } & 4.85 & 1.50\end{array}$

Perceptions of Victim-Wife

Perceptions of Perpetrator-

$\begin{array}{lll}\text { India } & 3.42 & 1.53 \\ \text { Iran } & 3.92 & 1.31 \\ \text { Malaysia } & 3.20 & 1.48 \\ \text { Pakistan } & 4.22 & 1.68\end{array}$

Husband

$\begin{array}{lll}\text { India } & 3.20 & 1.64 \\ \text { Iran } & 3.01 & 1.27 \\ \text { Malaysia } & 2.32 & 1.50 \\ \text { Pakistan } & 4.48 & 1.60\end{array}$

